\title{
The appendicular skeleton of Neuquensaurus, a Late Cretaceous saltasaurine sauropod from Patagonia, Argentina
}

\author{
Alejandro Otero \\ Acta Palaeontologica Polonica 55 (3), 2010: 399-426 doi: http://dx.doi.org/10.4202/app.2009.0099
}

Neuquensaurus, from the Late Cretaceous of Argentina and one of the first dinosaurs described from Patagonia, is one of the most derived sauropod dinosaurs, and its proportions and size place it among the smallest sauropods ever known. In this context, Neuquensaurus is central to understanding late stages of sauropod evolution. This contribution offers a full description of the appendicular skeleton of Neuquensaurus. The anatomical analysis reveals that the appendicular skeleton of Neuquensaurus exhibits unique characteristics only shared with closely related saltasaurine titanosaurs; for example, the laterally directed preacetabular lobe of the ilium, the prominent fibular lateral tuberosity, and the presence of an intermuscular line on the femoral shaft, which is proposed here as a synapomorphy of Saltasaurinae. Neuquensaurus also displays many reversals to primitive character states, such as the presence of a prominent olecranon process of the ulna, a trochanteric shelf, a lesser trochanter and an ischial tuberosity. Additional characters that allow its evaluation in a phylogenetic context are here provided. Among them are the extremely deflected femoral shaft, the elliptical femoral cross-section, and the anterolaterally oriented cnemial crest.

Key words: Sauropoda, Saltasaurinae, Neuquensaurus australis, Neuquensaurus robustus, appendicular anatomy, sauropod evolution, Patagonia, Argentina.

Alejandro Otero [alexandros.otero@gmail.com], CONICET_División Paleontología de Vertebrados, Museo de La Plata, Paseo del Bosque s/n, 1900 La Plata, Argentina.

This is an open-access article distributed under the terms of the Creative Commons Attribution License (for details please see creativecommons.org), which permits unrestricted use, distribution, and reproduction in any medium, provided the original author and source are credited. 
FoF Full text $(1,069.8 \mathrm{kB})$ 